\title{
Gênero, sexualidade e educação médica: vivências em uma escola federal que utiliza metodologias ativas de aprendizagem
}

\author{
Gender, sexuality and medical education: experiences in a federal school that uses active learning methodologies \\ Pedro Mendonça de Oliveira' (1) | pedrocsnc@gmail.com \\ Aline Guerra Aquilante1 (1) aline@ufscar.br \\ Rodrigo Otávio Moretti-Pires ${ }^{2}$ (1) rodrigo.moretti@ufsc.br \\ Sueli Fátima Sampaio' (1) sufasampaio@gmail.com
}

\section{RESUMO}

Introdução: A sexualidade se caracteriza como dispositivo de poder, e a medicina tem importante papel como uma das principais instituições de ação. A educação médica tende a ratificar o discurso heteronormativo e diagnosticar os padrões desviantes como patologia. Pauta-se na categorização binária dos indivíduos como implicação de sua sexualidade. O curso de Medicina investigado assume a proposta metodológica da espiral construtivista, que procura garantir o protagonismo dos estudantes, assim como dialoga com seus conhecimentos prévios, apostando no conceito de aprendizagem significativa.

Objetivo: Este estudo teve como objetivo analisar as experiências dos estudantes no desenvolvimento do perfil de competência relacionado a gênero e sexualidade durante o curso de Medicina.

Método: Trata-se de pesquisa qualitativa utilizando grupos focais com estudantes do sexto ano do curso.

Resultado: O estudo aponta para a percepção dos estudantes sobre a importância das metodologias ativas, bem como sobre a inserção precoce nos campos de prática. No entanto, a temática sobre gênero e sexualidade precisa estar proposta no elenco de disparadores para o uso da espiral construtivista.

Conclusão: As metodologias ativas de ensino-aprendizagem podem se configurar como estratégia contra-hegemônica ante o dispositivo da sexualidade na garantia de biopoder, na medida em que haja reorientação desses conteúdos no currículo.

Palavras-chave: Educação Médica; Currículo; Aprendizagem Baseada em Problemas; Identidade de Gênero; Sexualidade.

\section{ABSTRACT}

Introduction: Sexuality is characterized as a device of power and Medicine plays a key role as one of the main action institutions. Medical education tends to ratify the heteronormative discourse and diagnose deviant patterns as a pathology. It is based on the binary categorization of individuals as an implication of their sexuality. The assessed medical course assumes the methodological proposal of the constructivist spiral, which seeks to guarantee the protagonism of the students, as well as the dialogue with their previous knowledge, using the concept of Meaningful Learning.

Objective: To analyze the students' experiences in the development of the competence profile related to gender and sexuality during medical school. Method: It is a qualitative research using focus groups with students attending the sixth year of the medical course.

Result: The study indicates the students' perception of the importance of active methodologies, as well as the early inclusion in the fields of practice. However, the thematic of gender and sexuality needs to be proposed in the list of triggers for the use of the constructivist spiral.

Conclusion: The active teaching-learning methodologies can constitute a counter-hegemonic strategy in the face of the device of sexuality in guaranteeing biopower, as there is a reorientation of these contents in the curriculum.

Keywords: Medical Education; Curriculum; Problem-Based Learning; Gender Identity; Sexuality.

${ }^{1}$ Universidade Federal de São Carlos, São Carlos, São Paulo, Brasil.

2 Universidade Federal de Santa Catarina, Florianópolis, Santa Catarina, Brasil.

Editora-chefe: Daniela Chiesa.

Editora associada: Daniela Chiesa.

Recebido em 12/07/20; Aceito em 13/09/21.

Avaliado pelo processo de double blind reviw. 


\section{INTRODUÇÃO}

A vida em sociedade é marcada por diferentes dinâmicas e exercícios de poder, aspectos que muitas vezes escapam à percepção dos médicos em sua prática profissional. Michel Foucault ${ }^{1}$ analisa que tanto a medicina como a sexualidade estão envolvidas em processos sociais importantes. No que diz respeito ao que o autor chama de dispositivo da sexualidade, a construção de saberes e de práticas implicadas na prestação de serviços e nos cuidados de saúde parte de certas questões epistemológicas que orientam a sociedade ocidental desde o século XVII. Nesse contexto, a emergência de regras e normas, conhecimentos e vigilâncias sustentou instituições (sobretudo a Igreja e a família) que serviram de suporte para corroborar um progressivo processo de internalização de regulações do exercício do sexo e da vida social.

Uma contribuição importante de Foucault ${ }^{1}$ para o entendimento das relações entre a medicina e o controle da sexualidade refere-se a como certos conhecimentos, assim como desconhecimentos, sobre o uso dos corpos e dos prazeres foram objetos privilegiados de estudo, atenção e intervenção médicas, especialmente no que concerne à psiquiatrização da sexualidade. No mesmo processo, a relação entre o masculino e o feminino na sociedade ocidental é fundamental para entender tanto os papéis socialmente construídos como as hierarquias de poder estabelecidas, tal como defende Joan $\mathrm{Scott}^{2}$. Essa autora discorre acerca da percepção sobre as diferenças sexuais e como elas são empregadas para distinguir papéis na sociedade por meio de significados culturais e, consequentemente, posicionando-as em relações hierárquicas.

Por sua vez, a filósofa política Judith Butler ${ }^{3}$ aponta que gênero trata de "um conjunto de atos repetidos no interior de uma estrutura reguladora altamente rígida, a qual se cristaliza no tempo para produzir a aparência de uma substância de uma classe natural de ser".

Butler $^{3}$ defende que a identidade é assegurada por conceitos estabilizadores de sexo, gênero e sexualidade. O que é incoerente e descontínuo é também questionável, já que "as 'pessoas' só se tornam inteligíveis ao adquirir seu gênero em conformidade com os padrões reconhecíveis de inteligibilidade do gênero" ${ }^{\prime 3}$. Desse contexto, exige-se uma heterossexualidade estável e oposicional, dentro do binarismo.

Nessas bases, a sexualidade tem na medicina uma importante instituição, com poder de patologizar supostos desvios, assim como reforçar comportamentos "saudáveis", movimento quase nunca perceptível por parte daqueles que exercem a profissão ${ }^{1,4}$. Os cursos de Medicina se pautam por conteúdos com bases epistemológicas em categorias binárias e heteronormativas de forma que, ao abordarem os pacientes, tudo o que diverge é invisibilizado ou considerado desvio e doença.
As Diretrizes Curriculares Nacionais para os Cursos de Medicina $^{5}$ incitam que devem ser garantidas estratégias curriculares e extracurriculares centradas no aprendizado de competências para o cuidado das pessoas por uma perspectiva ampliada. Entretanto, há pouca especificidade de aspectos como gênero e sexualidade, ainda que exista ressonância com o que é registrado a respeito da educação profissional em saúde na Política Nacional de Saúde Integral de Lésbicas, Gays, Bissexuais, Travestis e Transexuais (LGBT) ${ }^{6}$.

Moretti-Pires ${ }^{7}$, em estudo com estudantes de Medicina heterossexuais e LGBTs, aponta para o silenciamento dos aspectos de gênero e sexualidade na educação médica. Ao mesmo tempo, o currículo oficial dos cursos, assim como o currículo oculto, leva ao reforço da atenção baseada em certo paradigma que concebe como normal a heterossexualidade, a cisgeneridade e o apagamento do feminino, exceto no que tange aos aspectos da reprodução.

A profissão médica tem papel-chave nas questões que envolvem a sexualidade e todos os desdobramentos que podem dela advir, tanto como dispositivo de biopoder na regulação das sexualidades como fator de autoconhecimento e saúde. Assim, este estudo tem como objetivo analisar, sob a perspectiva dos alunos, como se trabalha o desenvolvimento do perfil de competência relacionado a gênero e sexualidade durante um curso de Medicina que utiliza metodologias ativas de aprendizagem.

\section{MÉTODOS}

A pesquisa foi desenvolvida no curso de Medicina da Universidade Federal de São Carlos (UFSCar), que conta com 40 vagas de ingresso anual e utiliza metodologias ativas de ensino-aprendizagem na condução do curso desde sua implantação, em $2006^{8}$. A espiral construtivista $(E C)^{9}$, derivada da Aprendizagem Baseada em Problemas - ABP (Problem-Based Learning - PBL) e da problematização, confere protagonismo aos estudantes no processo de aprendizagem, apostando na aquisição de conhecimentos por meio de metacognição e metaprendizagem, ancorando novos conteúdos e significados nos repertórios prévios de conhecimento dos próprios estudantes. Esses são os pressupostos e fundamentos da Teoria da Aprendizagem Significativa ${ }^{10}$, que tem no professor o papel de facilitador do processo de aprendizado ${ }^{11}$.

Trata-se de uma pesquisa descritiva, de natureza qualitativa, que se preocupa com a compreensão interpretativa da ação social, a inteligibilidade desses fenômenos e o significado e a intencionalidade que lhe atribuem os atores envolvidos ${ }^{12}$. Tem como foco questionar um modelo positivista em busca de verdades objetivas que, somado à moralização em torno da sexualidade, prejudica a compreensão acerca da própria complexidade ${ }^{13}$. 
Para alcançar tais compreensões, o estudo utilizou a técnica de grupos focais como método de coleta de informações ${ }^{14}$. Participaram deste estudo dois grupos com características identitárias homogêneas que compartilham de uma mesma vivência: são estudantes do curso de Medicina da UFSCar.

Foram convidados a participar dos grupos focais todos os 40 alunos do sexto ano/2019 do curso de Medicina da UFSCar. Aceitaram e tiveram disponibilidade de participar 15 alunos, os quais foram divididos em dois grupos focais, de seis e nove participantes. A distribuição foi guiada pela disponibilidade dos alunos, conforme compatibilidade de agenda com outras atividades do internato médico.

A Tabela 1 mostra a composição dos grupos focais.

Utilizou-se um roteiro semiestruturado previamente testado com um grupo-piloto composto por seis estudantes recém-egressos do curso. Além das três questões disparadoras pensadas inicialmente, foi adicionada uma quarta questão para ser trabalhada com os sextanistas:

1) Gostaria que vocês relatassem como as questões de gênero e sexualidade são aprendidas durante o curso de Medicina da UFSCar.

2) Em que momentos questões relacionadas a gênero e sexualidade apareceram durante as atividades teóricas e práticas? Como vocês descreveriam a abordagem dos docentes e preceptores sobre elas?

3) $\mathrm{Na}$ percepção de vocês, como a condução das atividades curriculares por meio de metodologias ativas influenciou a abordagem desses conteúdos?

4) Vocês vivenciaram ou presenciaram situações durante o curso (encontros teóricos ou práticos) em que, ao falarem sobre esses temas, houve constrangimento por parte de qualquer pessoa envolvida (estudantes, pacientes, docentes etc.)? Se sim, poderiam descrevê-los?

Gravaram-se as sessões de grupo focal, e, posteriormente, as informações foram transcritas e codificadas. Utilizou-se a seguintecodificaçãopara preservaraidentidadedosparticipantes, segundo autodeclaração: a letra $\mathrm{H}$ inicial = Homem, $M=$ Mulher. A segunda letra $H=$ Heterossexual, enquanto $B=$ Bissexual, $G=$ Gay e L = Lésbica. Após o hífen, há a numeração dos grupos $\mathrm{G} 1$ e G2, conforme a sequência em que ocorreram. Compreende-se que o conjunto dessas características ajuda a entender o tipo de sensibilidade das falas, bem como o "lugar de fala" de cada participante. Nesse sentido, é fundamental registrar que todos os participantes são pessoas cisgênero e que em nenhum dos grupos havia participantes transexuais (binários ou não binários).

Para análise das informações, foi utilizado o Método de Interpretação de Sentidos ${ }^{15}$. Por sua perspectiva
Tabela 1. Caracterização e distribuição dos participantes da pesquisa.

\begin{tabular}{ccccc}
\hline \multicolumn{2}{c}{ Identificação } & Mulheres & Homens & Total \\
\hline \multirow{4}{*}{ Grupo 1} & Homossexuais & 0 & 0 & 0 \\
& Bissexuais & 3 & 0 & 3 \\
& Heterossexuais & 1 & 2 & 3 \\
\hline \multirow{3}{*}{ Grupo 2} & Homossexuais & 0 & 2 & 2 \\
& Bissexuais & 2 & 1 & 3 \\
& Heterossexuais & 2 & 2 & 4 \\
\hline \multirow{5}{*}{} & Total & 8 & 7 & 15 \\
\hline
\end{tabular}

socioantropológica, esse método tem como foco o fenômeno cultural. Sua trajetória de análise de significados é balizada pelas correntes compreensivistas das ciências sociais e considera palavras, ações, conjunto de inter-relações, grupos, instituições, conjunturas, entre outros campos analíticos. Assim, as informações coletadas nas entrevistas foram analisadas seguindo as três etapas previstas no Método de Interpretação de Sentidos:

1) Descrição: após a transcrição literal do material e leituras imersivas, produziram-se a síntese descritiva dos principais aspectos e a definição preliminar das categorias de análise.

2) Análise: por se tratar de um movimento de decomposição da síntese descritiva, traçou-se um caminho sistemático de busca de localizadores-chave explícitos (ou não) nas falas dos participantes. $O$ produto dessa etapa foi uma síntese mais ampliada, que estabelece relações entre os fatores dos depoimentos e consolida a escolha das categorias analíticas.

3) Interpretação: etapa que busca sentido nas falas e ações para alcançar compreensão ou explicação para além dos limites do que é descrito e analisado. $O$ produto dessa etapa é uma síntese que articula a análise dos depoimentos com os referenciais teóricos adotados ${ }^{1-3}$.

Vale ressaltar que essas três etapas de tratamento de dados qualitativos não possuem fronteiras claras entre si. $O$ importante é buscar a lógica interna do grupo ante o tema que está sendo analisado.

Este estudo foi apreciado e aprovado pelo Comitê de Ética em Pesquisa da UFSCar (Parecer n 3.045.004, de 28 de novembro de 2018), atendendo às exigências da Resolução no 466/2012 do Conselho Nacional de Saúde.

\section{RESULTADOS}

O grupo 1 foi composto de seis alunos de um mesmo grupo de internato médico, ou seja, que realizaram todos os 
estágios práticos juntos. O grupo focal foi realizado no intervalo entre as atividades no hospital universitário. Conforme descrito na Tabela 1, foi composto de quatro mulheres (três bissexuais e uma heterossexual) e dois homens (heterossexuais), e não necessariamente todos tinham afinidade ou interesse desperto pelas temáticas. As discussões oportunizadas por esse grupo foram proeminentes em termos da temática de gênero, com volume de fala expressivamente maior entre as mulheres do grupo. Aspectos relacionados à sexualidade não surgiram espontaneamente, mas foram provocados pelo moderador.

Em contrapartida, o grupo 2 possui mais heterogeneidade, tanto em relação ao gênero como no que concerne à orientação sexual, com dois homens gays, um homem bissexual, dois homens heterossexuais, duas mulheres bissexuais e duas mulheres heterossexuais. Esse grupo foi composto de alunos com mais afinidade com os temas. Os participantes se organizaram individualmente para a realização do grupo em data e horário sugeridos pelo pesquisador. Esse tipo de organização permitiu abarcar tanto gênero como sexualidade sem que houvesse necessidade de intervenção. Não se notou maior tendência a monopolizar a discussão para um dos dois temas. Entendeu-se que todos os participantes tiveram oportunidade de contribuir sem a necessidade de serem estimulados.

Embora o currículo do curso empregue metodologias ativas, há certa carência na abordagem de gênero e sexualidade durante a graduação de maneira direta em disciplinas, segundo a percepção dos estudantes. Porém, embora haja consenso entre os participantes de que não há qualquer atividade dirigida especificamente para tais temas, ou seja, isso não se encontra na ementa das atividades curriculares, a trajetória de inserção no campo de prática ao longo dos anos de graduação os colocou em contato com as questões de gênero e sexualidade. Nesse sentido, o uso diretivo em termos de metodologias ativas poderia promover maior segurança ao lidar com essa temática, uma vez que a criação de vínculo com os pacientes é um dos enfoques mais interessantes segundo os estudantes entrevistados.

Realmente na nossa grade curricular, formalmente, a gente não tem um contato, uma discussão nesse sentido, é um pouco mais direcionada pra você ter um, é... dirigir uma anamnese de forma adequada, um comportamento e criar um vínculo adequado com o paciente (MH-G2).

Acho que a gente ganha maturidade ao longo do curso e agora a gente tem mais segurança pra lidar com esse tema. Assim, se ele aparecesse no meu primeiro ano, na primeira exposição eu ia ficar com mais dedos, e agora no sexto ano eu tenho mais segurança pra lidar com paciente sobre essas questões, mas não que foi treinado especificamente pra isso. É um treinamento de ser médico (MB-G1).
Apesar dos ganhos em termos de abertura para o questionamento e para a incerteza que os estudantes registraram pelo uso das metodologias ativas, deve-se perceber que conceitos próprios da área de gênero e sexualidade não são familiares aos futuros médicos. Isso implica, muitas vezes, problemas para atuação mais técnica nas especificidades da saúde LGBTI+, assim como para construção de vínculos. Observou-se pouca fluidez ou familiaridade dos estudantes no tratamento de determinadas especificidades inerentes, especialmente na maneira de conduzir as intervenções médicas, mesmo em situações como a gravidez de pessoas trans.

Acho que a metodologia ativa ensina isso pra gente, que não tá errado não saber, e tá tudo bem eu perguntar, desde que eu pergunte com objetivo real de ajudar o paciente (HG-G2).

Na maternidade a gente atendeu uma mulher grávida, ela na verdade era trans, e ela estava grávida e o companheiro... não me lembro direito como era, mas o companheiro também era um homem, né?... era cis e homossexual... ela era uma mulher... era um homem trans, homossexual... e ela tava grávida, né?... ele tava grávido... (MB-G1).

A potência de se empregar a inserção precoce dos estudantes em cenários reais de prática parece estar relacionada à percepção de preparação acerca da relação médico-paciente. A experiência educacional dos estudantes desde a primeira série do curso permite construir uma relação singular, ética e mais humanizada para o cuidado em saúde. Assim, poderá ser a base para toda a graduação e vida profissional. Isso é reconhecido e valorizado por eles (estudantes), sobretudo quando analisado em contraste com o que acontece em outras instituições com currículos mais tradicionais ${ }^{16}$. Cabe ressaltar que esse potencial poderá ter grande importância na abordagem dos aspectos de gênero e sexualidade na atenção médica se essas dimensões das experiências dos pacientes forem abordadas de maneira articulada com o ensino do fazer médico.

Eu acho que a nossa inserção precoce na prática faz com que a gente desenvolva uma relação interpessoal, chega ao sexto ano com uma relação interpessoal muito mais polida do que nas outras faculdades, que têm o grosso disso no internato, em dois anos. Isso permite com que a gente chegue pra pessoa e faça perguntas muito mais natural, tratando aquilo com naturalidade (HB-G2).

$\mathrm{Na}$ percepção dos participantes, a utilização de metodologias ativas tem relação com um comportamento que entendem como proativo de busca do saber. Sinergicamente, o ganho de autonomia também faz com que os estudantes persigam o conhecimento quando as situações vivenciadas na prática dialogam com suas vivências prévias, característica 
fundamental do conceito de aprendizagem significativa: "Eu acho que a metodologia ativa ajuda com que a gente desenvolva um senso crítico e uma disposição pra busca do conhecimento que é grande, né? Proatividade mesmo" (MB-G1).

Chama a atenção o fato de que, a despeito da divulgação do tema do projeto de pesquisa, foi necessário levar à discussão de um dos grupos a pauta de como as questões de gênero e sexualidade (não) aparecem contempladas no curso. Foi registrado que os disparadores dessa temática vêm dos estágios vivenciados na atividade curricular "Prática Profissional". Conforme apontaram os participantes, vários aspectos mais amplos da vida do usuário, incluindo gênero e sexualidade, não aparecem como conteúdo curricular explícito. Portanto, para muitos, essa formação depende de sua própria busca, das vivências em uma prática médica articulada à temática, assim como de outros aspectos menos explorados na educação médica.

Vários aspectos da medicina não são dados propriamente como obrigatórios no nosso curso, mas ele prevê, sim, que na nossa prática a gente vai ver isso. Então com uma reflexão melhor, eu acho que sim, o curso proporciona isso pra gente. Porque é muito difícil você passar seis anos em contato com a prática e não ter uma discussão disso (HH-G2).

É, acho que realmente quando a gente estuda os ciclos de vida, que é uma coisa bem colocada nos primeiros anos, a questão da sexualidade aparece, sem dúvida, né? Então, fazendo essa reflexão mais aprofundada, acho que aparece de alguma forma, sim, e de uma forma um pouco mais prevista do que a gente tava falando (HG-G2).

Se você não for exposto em algum momento do curso também, você não tem uma grade que te prepare pra depois. Eu não me lembro de ter uma atividade que prepare pra isso... No meu caso, que chego aqui um pouco mais velho, dá pra ver que há uma diversidade sexual maior do que eu imaginava antes de ingressar na faculdade. Mas acredito que a faculdade não me preparou, não me deu aulas de como lidar assim com isso (HH-G1).

A despeito do silenciamento de espaços e discussões formativas em termos de gênero e sexualidade, a relevância da temática para a formação médica foi apontada como parte da preocupação dos participantes. Isso acontece, especialmente, no trabalho de enfoques que permitam a abordagem dos pacientes de maneira não estigmatizante, que garantam um cuidado ampliado e que incluam essas dimensões.

Eu acho que se as nossas situações-problema [SPs], elas querem ser um reflexo da sociedade, eu acho que seria muito fácil colocar casais homossexuais nas SPs, porque, enquanto não tratar com normalidade, sempre vai ser um tabu, sempre a gente vai achar difícil comentar sobre isso. Porque é uma coisa que a gente vai vivenciar na prática, então acredito que essa seria uma maneira de inserir o assunto dentro da graduação. Da mesma forma que hoje em dia estão aparecendo casais gays nas novelas e daí por diante... (HB-G2).

Eu acho que, assim, o que fica de medo pra mim da inserção desses assuntos é justamente o estigma. Por exemplo, quando surgiu uma paciente lésbica, ela tinha SOP [síndrome dos ovários policísticos], ela tinha características mais masculinas, entre aspas. E eu acho que eu tenho medo disso, por exemplo, de surgir um casal homossexual na SP de Aids (MB-G2).

\section{DISCUSSÃO}

O fato de não haver qualquer atividade curricular dirigida aos temas de gênero e sexualidade encontra ressonância nos achados de Moretti-Pires ${ }^{7}$, trabalho no qual houve marcadamente o silêncio sobre a temática na formação de estudantes de Medicina de outra universidade federal. Esse outro curso é conduzido por meio de metodologias de ensino tradicionais e, segundo os alunos, também não possuía nada relacionado a gênero e sexualidade nas disciplinas, o que é interessante para apontar que as metodologias ativas em si não dão conta de diversos recortes da realidade e da sociedade.

A compreensão da metodologia ativa externalizada pelos participantes da pesquisa denota um ponto de contato importante com a noção da abordagem dialógica de competência ${ }^{17}$. Outro resultado, bastante significativo, contrasta com os achados de Moretti-Pires ${ }^{7}$ acerca da postura dos estudantes diante do desafio de aprender. Enquanto os sujeitos da pesquisa revelam um posicionamento de conforto perante a dúvida, o que segundo a fala do próprio aluno é desdobramento da metodologia ativa, a percepção de estudantes de Medicina submetidos a currículos e metodologias tradicionais é de que a dúvida não deve existir. Há a impressão de que o fato de o indivíduo ser um estudante do curso de Medicina já caracteriza que ele sabe tudo de antemão. Além disso, perguntas geralmente não são bem-vindas, sobretudo se direcionadas aos docentes. Os alunos não são ensinados a problematizar nem seu conhecimento, nem sua prática, o que torna aquele contexto um espaço empobrecido em relação à crítica e reflexão.

O que se encontra neste trabalho pode surgir como uma quebra do paradigma da formação médica indicada por Foucault ${ }^{1}$ e reforçada na tese de Moretti-Pires ${ }^{7}$, em que silenciar o estudante em sala de aula é função docente. Conforme Foucault", "a segurança médica está embrenhada na rede construída pelo feixe de relações e sentidos, que operam o biopoder"; por isso, há que se valer da "vigilância hierarquizada"; 
uma hierarquia progressiva presente, porém funcionando em "silêncio". No silêncio aprendido pelo estudante. No silenciar daqueles hierarquicamente inferiores.

A Política Nacional de Saúde Integral de Lésbicas, Gays, Bissexuais, Travestis e Transexuais recomenda formalmente a inclusão de conteúdo curricular relacionado à saúde LGBT como temática obrigatória, o que envolve: terminologia básica relacionada à população LGBT, questões de entrevista que facilitem a abertura do tema de orientação sexual e identidade de gênero, informações a respeito do impacto do heterossexismo e homofobia, bem como a necessidade de cuidados de saúde específicos de populações minoritárias sobre identidade de gênero e sexual ${ }^{6}$. O que se observou no presente estudo corrobora a reiterada importância de integrar a temática de saúde LGBT de forma obrigatória e de construir mecanismos de apoio à estruturação pedagógica do conteúdo, no sentido de auxiliar as atividades curriculares a cumprir seu papel.

É possível inferir que os alunos assumem a relevância dos temas, sem entendê-los como patologias. Durante as discussões nos grupos, foram debatidas formas de inserir tais assuntos nas atividades curriculares com naturalidade, leia-se, sem preconceito ou juízo de valor.

Com relação à aprendizagem a partir de situaçõesproblema (SPs), que têm como função primordial, nos movimentos da EC, fornecer elementos para criação de hipóteses e questões de aprendizagem, os alunos demonstraram possuir bom conhecimento acerca da forma como devem ser trabalhadas. Para que isso aconteça, segundo Lima e Linhares ${ }^{18}$, as SPs devem conter

[...] uma visão ampliada, integrada e integradora dos temas imprescindíveis a serem estudados, contemplando diferentes aspectos do processo saúde-doença [...] e identificando as dimensões biopsicossociais. Para isso, devem seguir alguns princípios como: realizar uma descrição dos fenômenos abordados no problema da forma mais neutra possível, formular o problema de forma concreta, minimizar os distratores do texto, guiar o aprendizado a um número limitado de itens, e conter itens que utilizem as informações prévias dos discentes.

Este trabalho não se dedicou a discutir a capacidade dos docentes do curso em preparar e conduzir as atividades curriculares por meio das estratégias previstas nas metodologias ativas, como as SPs, ainda que para alguns autores, como Tomaz ${ }^{11}$, a expertise no processo de facilitação seja mais importante do que a expertise no tema a ser estudado. É também relevante observar que quase todos os estudiosos do tema concordam ser desejável algum grau de aproximação com a temática, suficiente para permitir um redirecionamento do grupo em casos nos quais as discussões se desviem do eixo proposto pelo problema.

Apesar de os cursos estarem tentando reestruturar seus projetos pedagógicos no que diz respeito à saúde de populações marginalizadas, há autores que entendem ainda não haver respostas sobre as melhores metodologias a serem utilizadas para alcançar os objetivos propostos ${ }^{19}$.

Faz-se pertinente comentar que é amplamente reconhecida a quase inexistência, nas escolas médicas, de preparo específico para os professores no terreno pedagógico. A competência na área técnica de atuação médica tem sido o critério fundamental para a seleção ou eleição dos profissionais que vão passar de médicos a pesquisadores e professores. Isso implica a existência de profundo desconhecimento de técnicas e metodologias de ensino, de trabalho com grupos e de produção de materiais didáticos apropriados ${ }^{20}$.

O presente artigo trouxe como enfoque principal a temática de gênero e diversidade sexual na formação médica, uma pauta que ganhou visibilidade na sociedade a partir das pautas feministas. Nesse sentido, as desigualdades e iniquidades de gênero impactam a saúde das pessoas. Devese considerar que situações de violência baseadas em gênero devem ser discutidas na educação médica com enfoque nos processos vivenciais e de relações das mulheres nos âmbitos externo e doméstico e nas relações de intimidade, com ampliação da sensibilidade e olhar dos futuros médicos para essas outras dimensões das questões aqui apresentadas.

\section{CONCLUSÕES}

Os resultados apontaram para importantes avanços em termos de formação médica no emprego das metodologias ativas e no contato com a realidade. No entanto, sinalizaram a necessidade de ações e estratégias mais direcionadas à discussão de gênero e sexualidade na abordagem com os pacientes durante o curso como um todo. A formação foi de certa forma espontânea e indireta, o que não garante necessariamente a mesma oportunidade para todos os estudantes, uma vez que os conceitos de gênero e sexualidade não foram mobilizados de maneira fluida e integrada às práticas médicas, inclusive com a necessidade de maior explicitação para disparar a discussão em um dos grupos focais.

A inserção precoce dos estudantes na realidade foi apontada como positiva, com grande potencial para abordagens que levem em consideração outras dimensões da vida do paciente, incluindo as questões de gênero e sexualidade.

Embora ainda em volume relativamente inexpressivo em âmbito nacional, publicações envolvendo gênero e sexualidade têm ganhado espaço dentro de revistas e periódicos. Este trabalho traz contribuições importantes acerca de possíveis 
caminhos a serem seguidos, no que diz respeito à potência das metodologias de ensino-aprendizagem na abordagem de tais temas.

\section{CONTRIBUIÇÃO DOS AUTORES}

Pedro Mendonça de Oliveira foi responsável pela concepção do estudo, revisão de literatura, produção e análise dos dados, escrita do artigo e aprovação da versão final do manuscrito. Aline Guerra Aquilante orientou a dissertação de mestrado de Pedro Mendonça de Oliveira e participou da concepção do estudo e da escrita e aprovação da versão final do artigo. Sueli Fátima Sampaio e Rodrigo Otávio Moretti-Pires participaram da concepção do estudo e da escrita e aprovação da versão final do artigo.

\section{CONFLITO DE INTERESSES}

Declaramos não haver conflito de interesses.

\section{FINANCIAMENTO}

O financiamento da taxa de publicação foi realizado pelo Programa de Pós-Graduação em Gestão da Clínica (PPGGC) da Universidade Federal de São Carlos (UFSCar).

\section{REFERÊNCIAS}

1. Foucault M. História da sexualidade 1: a vontade de saber. Rio de Janeiro: Paz e Terra; 2015.

2. Scott J. Gênero: uma categoria útil de análise histórica. Educ Real. 1990;15(2):5-22.

3. Butler J. Problemas de gênero: feminismo e subversão da identidade. Rio de Janeiro: Civilização Brasileira; 2015.

4. Davy Z. Recognizing transsexuals: personal, political and medicolegal embodiments. London: Ashgate; 2011.

5. Brasil. Resolução CNE/CES n 3, de 20 de junho de 2014. Diretrizes Curriculares Nacionais do Curso de Graduação em Medicina. Brasília: Ministério da Educação; 2014.
6. Brasil. Política Nacional de Saúde Integral de Lésbicas, Gays, Bissexuais, Travestis e Transexuais. Brasília: Ministério da Saúde; 2011.

7. Moretti-Pires RO. Domesticando corpos, construindo médicos: das relações de gênero a uma sociologia da profissão [dissertação]. Florianópolis: Universidade Federal de Santa Catarina; 2017.

8. Adler MS, Gallian DMC. Escola médica e o Sistema Único de Saúde (SUS): criação do curso de Medicina da Universidade Federal de São Carlos, SP, Brasil (UFSCar) sob a perspectiva de docentes e estudantes. Interface (Botucatu). 2016;22(64):237-49.

9. Lima VV. Espiral construtivista: uma metodologia ativa de ensinoaprendizagem. Interface (Botucatu). 2017;21(61):421-34.

10. Ausubel D. Aquisição e retenção de conhecimentos: Uma perspectiva cognitiva. Lisboa: Plátano Edições Técnicas; 2000.

11. Tomaz JB. O papel e as características do professor. In: Mamede S, Penaforte J, organizadores. Aprendizagem baseada em problemas: anatomia de uma nova abordagem educacional. São Paulo: Hucitec; 2001 p. $157-82$.

12. Minayo MCS. Pesquisa social: teoria, método e criatividade. Petrópolis: Vozes; 1993.

13. Gamson J. As sexualidades, a teoria queer e a pesquisa qualitativa. In: Denzin NK, Lincoln YS, organizadores. O planejamento da pesquisa qualitativa. Porto Alegre: Artmed; 2010. p. 145-60.

14. Deslandes SF. Trabalho de campo: construção de dados qualitativos em quantitativos. In: Minayo MCS, Assis SG, Souza ER, organizadoras. Avaliação por triangulação de métodos: abordagem de programas sociais. Rio de Janeiro: Fiocruz; 2006. p. 157-84.

15. Gomes R, Souza ER, Minayo MCS, Malaquias JV, Silva CFR. Organização, processamento, análise e interpretação de dados: o desafio da triangulação. In: Minayo MCS, Assis SG, Souza ER, organizadoras. Avaliação por triangulação de métodos: abordagem de programas sociais. Rio de Janeiro: Fiocruz; 2006. p. 185-222.

16. Gonçalves JV, Gonçalves RC, Silva RF. Cuidado à saúde e a formação do profissional médico. Rev Bras Educ Med. 2018;42(3):9-15.

17. Lima VV. Competence: different approaches and implications in the training of healthcare professionals. Interface Comun Saúde Educ. 2005;9(17):369-79.

18. Lima GZ, Linhares REC. Escrever bons problemas. Rev Bras Educ Med. 2008;32(2):197-201.

19. Oliveira MFR, Castanho JLCO, Rorigo SC. Saúde e marginalização social: suprimindo falhas curriculares. Rev Bras Med Fam Comunidade. 2019;14(41):1793. doi: 10.5712/rbmfc14(41)1793.

20. Feuerkewer LC. Além do discurso de mudanças na educação médica. São Paulo: Hucitec; 2000. p.10-44. 